\title{
Estimating the Costs of Operating Reserve Provision by Poundage Hydroelectric Power Plants
}

\author{
Roman Petrichenko, Karlis Baltputnis, Dmitry Sobolevsky, Antans Sauhats \\ Institute of Power Engineering \\ Riga Technical University \\ Riga, Latvia \\ romans.petricenko@rtu.lv, karlis.baltputnis@rtu.lv,dmitrijs.sobolevskis@rtu.lv, sauhatas@eef.rtu.lv
}

\begin{abstract}
The transmission system operators are entrusted with the task of ensuring stable and reliable functioning of the power system. In a modern power system, there are three groups of market actors who can be called upon by TSOs to aid in power system operation management: controllable generation, energy storage and controllable load. The owners of these assets can rightfully expect remuneration for their services from the TSO to recoup investment costs and operational expenses. This study is focused on poundage hydroelectric power plants and it strives to estimate the cost of operating reserve provision. Data of the large hydroelectric power plants located on the River Daugava is used for the calculation of costs and validation of the proposed algorithms.
\end{abstract}

Index Terms--optimization, hydroelectric power, hydropower scheduling, reserve cost assessment.

\section{INTRODUCTION}

There are several different value streams power plants managed under market conditions can tap into to maximize their revenue. Some of the most prominent avenues depending on the setup of particular power systems are the day-ahead, intra-day and balancing markets. The latter essentially serve the purpose of providing reserves which depending on their technical specifications and application can be further divided into automatic frequency containment reserves, frequency restoration reserves (manual or automatic) and replacement reserves.

The operating reserves are an essential tool in the hands of transmission system operators (TSO) who are entrusted with the task of ensuring stable and reliable functioning of the power system. Additionally, in order to fulfill their main goal, TSOs are also in charge of frequency control, power flow control, maintaining balance between power supply and consumption etc. With the rise of intermittent renewable energy sources, the importance and complexity of above-mentioned tasks grows rapidly [1]. In a modern power system, there are three distinct groups of market actors who can be called upon by TSOs to aid in power system operation management: controllable generation, energy storage and controllable load. Therefore, the owners of not only traditional power plants, but also distributed generation (micro cogeneration, solar power stations with

This work has been supported by the European Regional Development Fund within the Activity 1.1.1.2 "Post-doctoral Research Aid" of the Specific Aid Objective 1.1.1 "To increase the research and innovative capacity of scientific institutions of Latvia and the ability to attract external financing, investing in human resources and infrastructure" of the Operational Programme "Growth and Employment" (No. 1.1.1.2/VIAA/1/16/021).

The work presented in this paper has also been co-financed by the National Research Program LATENERGI (2014-2017).

978-1-5386-1488-4/18/\$31.00 C2018 IEEE energy storage elements, small hydro power stations, biomass plants etc.) and aggregated consumer devices can become market players. On the other hand, the owners of generation, storage or controllable load can rightfully expect remuneration for their services from the TSO to recoup investment costs and operational expenses. This study is focused on the opportunity costs reserve provision incurs on poundage hydroelectric power plants (HPP), which is an important step towards formulating fair and justified bids in reserve markets.

Poundage HPPs are characterized by their fast start-up and regulation, and limited water storage abilities which highlight a high potential in providing operating reserves, both spinning and non-spinning. However, the main income of such power plants derives from participation in energy wholesale markets, thus operating reserve provision imposes additional constraints on finding the optimal day-ahead schedule and subsequently decreases the value that can be extracted there. The peculiarity of poundage HPPs lies in them being somewhere between runof-river plants who have no storage capabilities and reservoir HPPs where planning of water resources can be carried out at a seasonal scale.

When solving the problem of HPP profit maximization it is paramount to consider the volatility of energy prices [2] and water inflow as well as a multitude of environmental restrictions. A significant number of publications have been devoted to solving this problem.

The probabilistic behavior of power system in operating reserve cost estimation is considered in [3]-[5]. The power system operation under different energy market setups is outlined in [6], [7].

The particular contribution of this study is using our previously developed HPP day-ahead scheduling optimization model and real world data to estimate the opportunity costs of operating reserve provision.

To assess the costs incurred due to the provision of operating reserves, the day-ahead scheduling optimization is carried out thrice with distinct operational modes (OM) in mind: 
- Participation in the day-ahead electricity wholesale market without additional constraints imposed by operating reserve provision. Let us call this $\mathrm{OM}$ as reserve-free (RF).

- Participation in the day-ahead electricity wholesale market with additional constraints imposed by spinning reserve provision (SR).

- Participation in the day-ahead electricity wholesale market with additional constraints imposed by nonspinning reserve provision (NSR).

The minimal compensation required for spinning or nonspinning reserve provision can be established by comparing the revenue obtained from the day-ahead market in the RF mode to the revenue in either SR or NSR modes (Fig. 1). The difference in the revenue marks the opportunity cost of reserve provision in the particular mode, the minimum remuneration required can afterwards be established by adding the opportunity cost to the day-ahead price in the particular hour.

Such evaluation of maintaining reserves can be used by the owners of:

- Hydroelectric power plants when preparing a proposal for operator's intra-day and balancing market bids.

- Managers of numerous small energy sources, either operational or merely in the design stage, when deciding on participation in the balancing of the power system.

The case study presented in this paper is based on the three cascaded poundage HPPs on the river Daugava, Latvia. While the full capacity exceeding $1500 \mathrm{MW}$ can only be achieved for a short period of time during the annual spring flood season, the HPPs are nevertheless an important player in providing and managing the electrical energy supply in the Baltic states. In the study, different scenarios are considered to better reflect the effect price and inflow volatility, HPPs water resources management and reserve size has on their provision costs.

The rest of this paper is organized as follows. Section II presents the problem formulation and solution methodology. Section III provides a brief description of the object under study. Numerical examples are presented and discussed in Section IV and Section V concludes the paper.

\section{TASK STATEMENT}

\section{A. Definition of the problem}

In all the OMs, a unit commitment problem has to be solved. The task formulation for the three cascaded poundage HPPs in the RF mode has been presented in previous articles [8], [9]. In the present paper, the reformulation of the optimization task (Fig. 1) involves maximization of revenues for the three OMs and determination of reserves maintenance costs as the difference between the first and remaining OMs.

In a competitive electricity market, the main goal of the market player is profit maximization. In our case, the optimal daily production schedule is obtained on a day-ahead basis with hourly resolution with water inflow, electricity price and reserved energy in each hour (power) as input data.

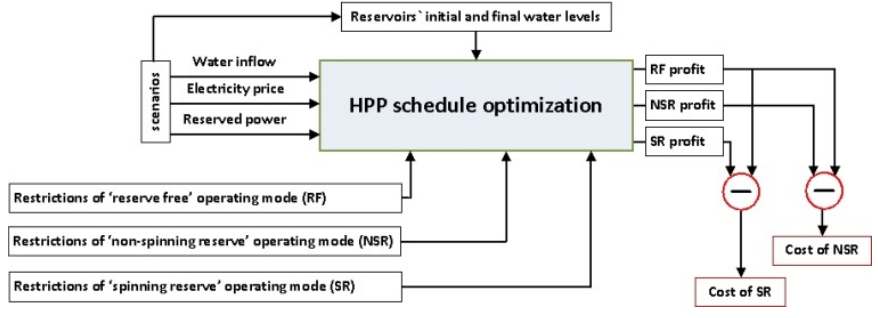

Figure 1. Flowchart of operational reserve provision cost estimation.

The aim of the producer for day-ahead market could be presented as:

$$
\sum_{t=1}^{N}\left(\sum_{k \in\{1,2,3\}} P_{t}^{k}\right) \cdot C_{t} \rightarrow \max
$$

where: $\mathrm{N}$ - number of hours; $\mathrm{k}$ - the variable of set $\{1,2,3\}$, which marks a specific HPP in the cascade, $P_{t}^{k}-$ generated power of specific HPP $k$ at hour $t$ (MW); $C_{t}$ - electricity price at $t$ hour.

In turn, the power production in an HPP depends on several parameters:

$$
P_{t}^{k}=\mathrm{f}_{P}\left(\eta_{t}^{k}, \Delta h_{t}^{k}, Q_{t}^{k}\right),
$$

where: $\eta_{t}^{k}$ - efficiency of the HPP $k$ at hour $t(\%), \Delta h_{t}^{k}-$ water discharge (change in reservoir level) at HPP $k$ at hour $t$ (m), $Q_{t}^{k}-$ water inflow at HPP $k$ at hour $t\left(\mathrm{~m}^{3} / \mathrm{s}\right)$.

The problem (1) has to be solved taking into account a number of technical and environmental constraints [10]-[12]. In general, a stochastic nonlinear optimization problem (1) can be divided into three interconnected parts: forecast of future processes $\left(C_{t}, Q_{t}^{k}\right)$; formulation of the objective function; solution of the maximization problem.

At the second operation mode (SR), the problem (1) must be solved taking into account additional conditions:

$$
P_{\text {rez }_{t}}^{k} \leq P_{t}^{k} \leq P_{\text {max }_{t}}^{k}
$$

where: $P^{k}{ }_{\text {rez }_{t}}-$ minimal power reserve of HPP $k$ at hour $t$ (MW), $P_{\text {max }_{t}}^{k}-$ maximal capacity of HPP $k$ at hour $t(\mathrm{MW}), P_{t}^{k}$ - active power generation of HPP $k$ at hour $t$ (MW).

Third operation mode (NSR) requires us to take into account the small but not equal to zero probability that the nonspinning reserve can be activated. When planning this reserve, we solve the problem (1) assuming that the reserves will not be used, but we need the constraints to be respected also in the opposite case, when they are fully activated. Thus, the solution of the optimization problem (1) for the NSR mode is subjected to:

- $\quad$ upper bounds of generated power;

- limitation of maximal water discharge permissible to not hinder activation of reserves, which can be expressed by substituting the required reserve power in 
equation (2) with water used for reserve activation $\Delta h_{\mathrm{rez}_{t}}^{k}$ :

$$
\left\{\begin{array}{c}
\Delta h_{t}^{k} \leq \Delta h_{\max _{t}}^{k}-\Delta h_{\mathrm{rez}_{t}}^{k} \\
\Delta h_{\max _{t}}^{k}=\mathrm{f}_{\Delta h_{t}^{k}}\left(\eta_{t}^{k}, P_{t}^{k}, Q_{t}^{k}\right) \\
\Delta h_{\mathrm{rez}_{t}}^{k}=\mathrm{f}_{\Delta h^{k}}\left(\eta_{t}^{k}, P_{\mathrm{rez}_{t}}^{k}, Q_{t}^{k}\right)
\end{array}\right.
$$

\section{THE POWER SYSTEM AND OBJECT UNDER STUDY}

The three poundage hydroelectric power plants' located on the River Daugava (Fig. 2) are used for the validation of the proposed assessment algorithm. The total installed capacity of Plavinas HPP is $893.5 \mathrm{MW}$ (the second largest HPP in the EU in terms of power [13]), Kegums HPP - 266 MW and Riga HPP $-402 \mathrm{MW}$.

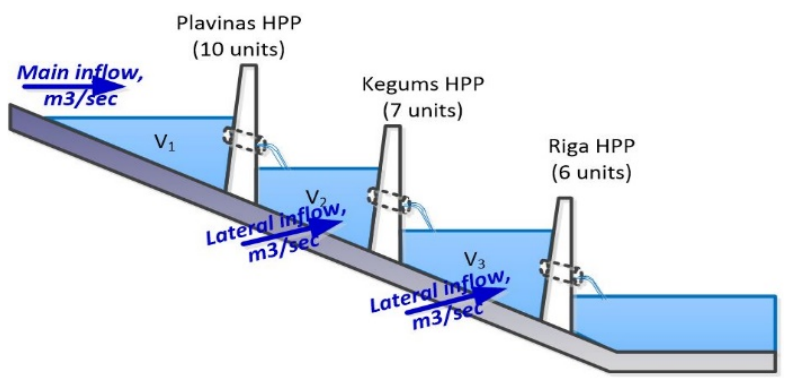

Figure 2. Layout of the HPP cascade [9].

The operation of HPPs is subject to numerous limitations due to environmental and safety concerns. The constraints imposed by bank erosion, reservoir capacity, integrity of dam facilities and various other factors [8], [9] are summarized in Table I.

TABLE I. ENVIRONMENTAL CONSTRAINTS OF THE HPPS IN CASCADE

\begin{tabular}{|c|c|c|}
\hline HPP & Type of constraint & Value \\
\hline \multirow{3}{*}{ Plavinas } & Upstream level, m & $72.0-67.0$ \\
\hline & $\begin{array}{l}\text { Permitted maximum hourly decrease in } \\
\text { reservoir level, } \mathrm{m} / \mathrm{h} \text { (depends on the season) }\end{array}$ & $0.2-0.3$ \\
\hline & $\begin{array}{l}\text { Permitted maximum daily decrease in reservoir } \\
\text { level, } \mathrm{m} / \text { day (depends on the season) }\end{array}$ & $1.5-0.75$ \\
\hline \multirow{3}{*}{ Kegums } & Upstream level, m & $32.0-30.4$ \\
\hline & $\begin{array}{l}\text { Permitted maximum hourly decrease in } \\
\text { reservoir level, } \mathrm{m} / \mathrm{h} \text { (depends on the season) }\end{array}$ & $0.2-0.3$ \\
\hline & $\begin{array}{l}\text { Permitted maximum daily decrease in reservoir } \\
\text { level, } \mathrm{m} / \text { day (depends on the season) }\end{array}$ & $1.6-0.6$ \\
\hline \multirow{3}{*}{ Riga } & Upstream level, $\mathrm{m}$ & $18.0-17.0$ \\
\hline & $\begin{array}{l}\text { Permitted maximum hourly decrease in } \\
\text { reservoir level, } \mathrm{m} / \mathrm{h} \text { (depends on the season) }\end{array}$ & $0.2-0.3$ \\
\hline & $\begin{array}{l}\text { Permitted maximum daily decrease in } \\
\text { reservoir level, m/day (depends on the season) }\end{array}$ & $1.0-0.75$ \\
\hline
\end{tabular}

\section{CASE STUDY}

The proposed cost assessment algorithm for operating reserve provision allows us to consider a relatively wide range of power producer behaviors depending on the volatility of external (water inflow, energy price etc.) and internal processes (efficiency, technical and ecological restrictions etc.).
There can be a huge number of variations in initial and final water levels, but due to space constraints we will focus on one particular case when the initial and final upstream water levels of an HPP are equal. In this case study, they are set at $71.05 \mathrm{~m}$, $31.59 \mathrm{~m}$ and $17.64 \mathrm{~m}$.

In Fig. 3, three input series of water inflow are shown. The curve form is based on the real-world data of 11/04/2015 and the series differ by amplitude. Input series for energy price are presented in Fig. 4. As in the previous case, they differ only by the absolute values. Such an assumption allows us to retain the character of the curves.

Radar chart in Fig. 5 illustrates different reserve provision cases studied. In most of the scenarios ('A', 'B', 'C', 'D', ' $E$ '), the required reserves differ in amount but not in their time of readiness. They are set to be maintained during the hours with the highest day-ahead price ( $8 \mathrm{AM}-5 \mathrm{PM})$. A subcase of scenario ' $\mathrm{A}$ ' is also considered, 'A1', where the reserves have to be maintained at hours of relatively cheap electricity (1 AM - 10 AM) instead. The differences in ' $A$ ' and ' $A 1$ ' scenarios is better reflected in Fig. 6 . They briefly overlap from $8 \mathrm{AM}-$ 10 AM.

Results of cost estimation of spinning and non-spinning reserve provision using the proposed methodology are shown in Fig. 7 - Fig. 12.

The costs of non-spinning reserve provision of $4500 \mathrm{MWh}$ (Scenario 'A') at variations of energy price and main inflow are depicted in Fig. 7. At higher energy price and water inflow, the highest costs of $1 \mathrm{MW}$ of non-spinning reserve provision are observed.

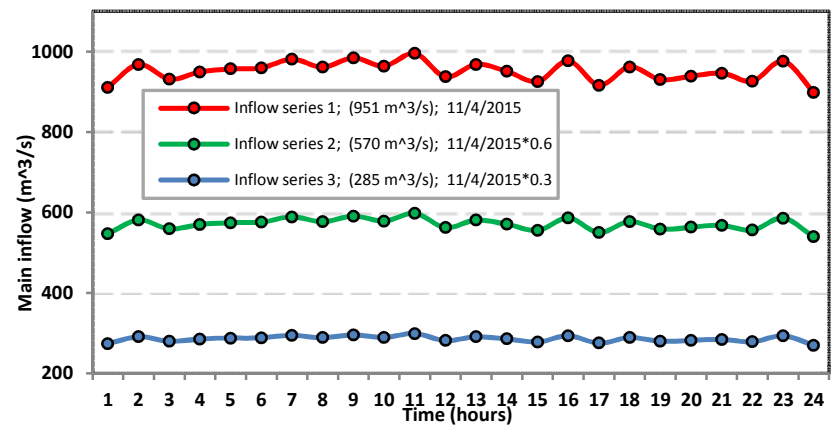

Figure 3. Actual water inflow on 11/04/2015 and its two variants [9].

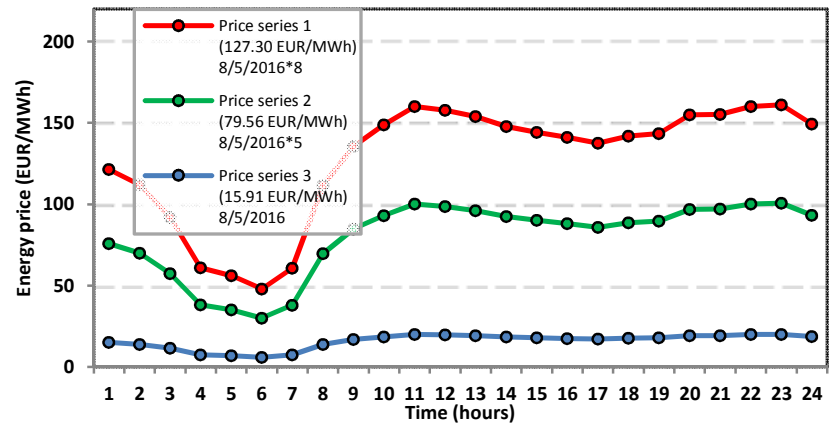

Figure 4. Actual day-ahead price on $8 / 5 / 2016$ and its two variants [2]. 


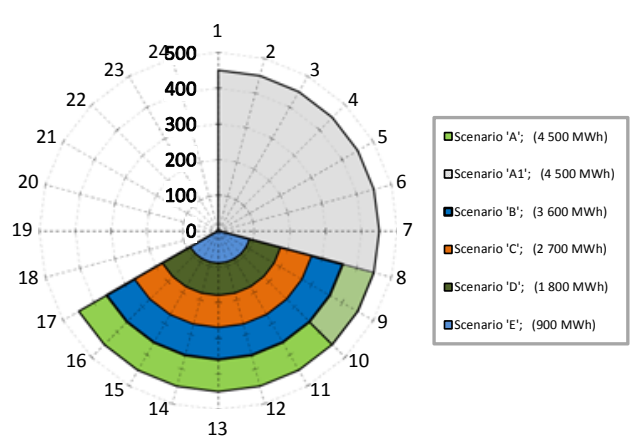

Figure 5. Reserve provision scenarios $(\mathrm{MWh} / \mathrm{h})$

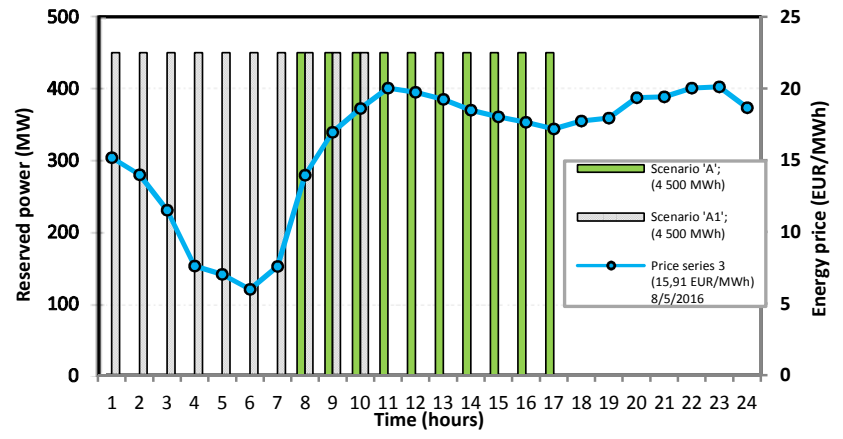

Figure 6. ' $\mathrm{A}$ ' and 'A1' reserve provision scenarios in relation to electricity day-ahead price

The costs of spinning reserve provision are depicted in Fig. 8. At the highest energy prices and water inflow, the generating units have to work in suboptimal conditions. In some cases, it is impossible to satisfy the constraints (3) or environmental or technical restrictions when solving the problem (1), i.e., the desired amount of reserve energy cannot be maintained, mainly due to insufficient inflow. These situations in the figures are marked with a red cross in a grey box.

The situation is very similar in the ' $\mathrm{Al}$ ' scenario where the amount of reserved power is the same, but the hours when it is necessary are moved to earlier in the day to an off-peak time. Fig. 9 and Fig. 10 show the reserve provision costs for the NSR and SR modes respectively. The general conclusion remains the same: higher inflow and electricity day-ahead price values result in higher reserve provision costs. However, curiously the non-spinning reserve has lower costs in the ' $\mathrm{A} 1$ ' scenario compared to the ' $\mathrm{A}$ ' scenario, whereas for spinning reserve the contrary is true and it is significantly more expensive in the 'A1' scenario.

The results of ' $\mathrm{B}$ ' scenario are not illustrated due to space constraints, but they are similar in form to the 'A' scenario for the NSR mode with $1.71 € / \mathrm{MWh}$ being the highest additional opportunity cost, whereas for the SR mode, the plot is similar to the results for ' $\mathrm{C}$ ' scenario (Fig. 12) with $15.24 € / \mathrm{MWh}$ as the highest cost.

The ' $\mathrm{C}$ ' scenario is indeed somewhat peculiar in that for the medium inflow case the cost is almost as large as in the high inflow case for NSR mode (Fig. 11) and even higher in the SR mode (Fig. 12). Furthermore, in the low inflow case the desired reserve power could not be provided.

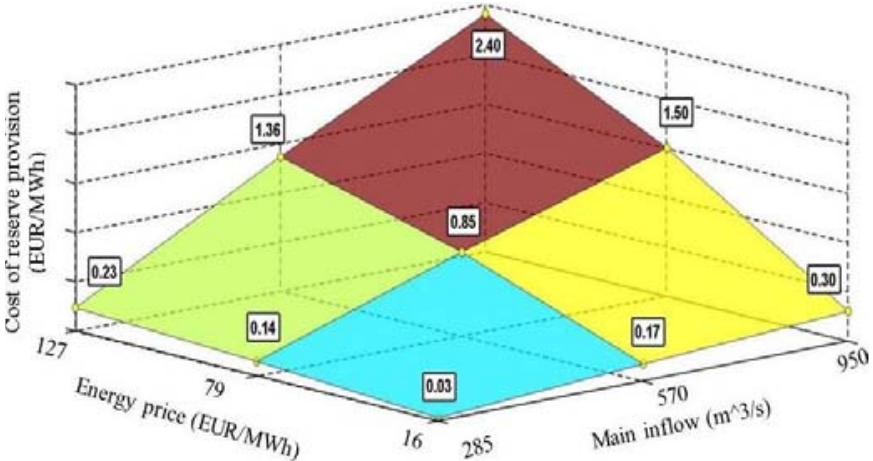

Figure 7. Costs due to non-spinning reserve provision at 'A'scenario with varying average energy prices and water inflow

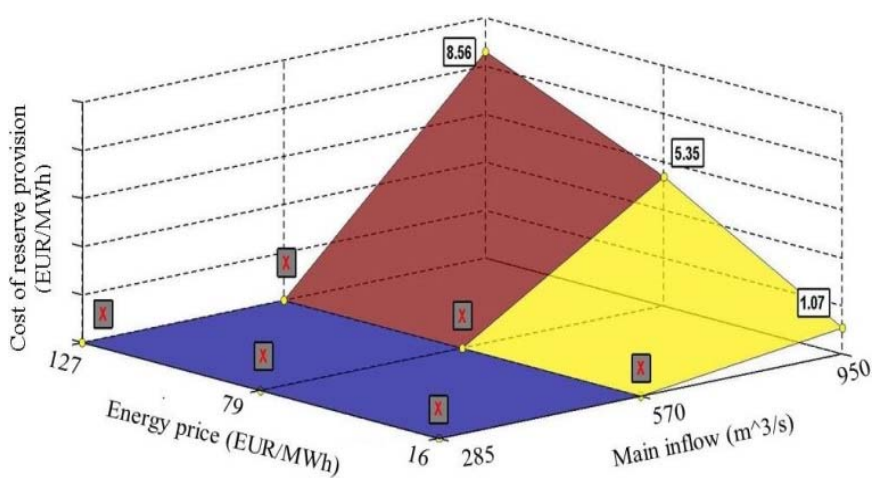

Figure 8. Costs due to spinning reserve provision at 'A'scenario with varying average energy prices and water inflow

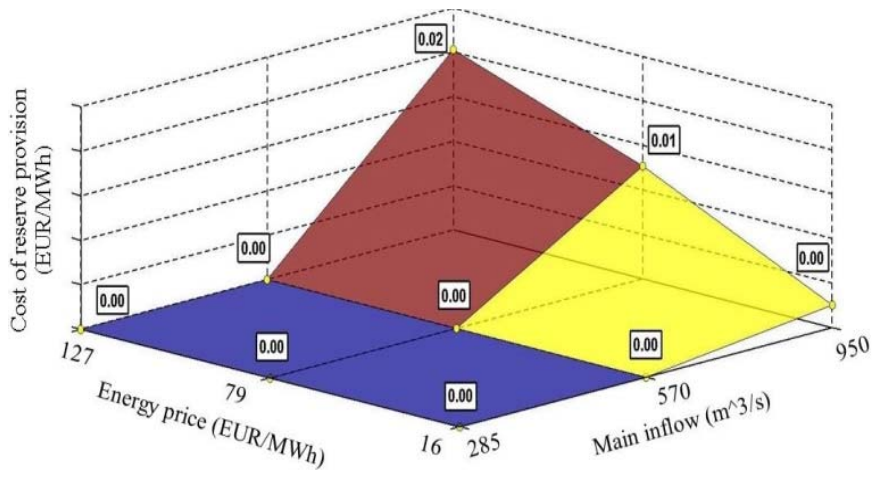

Figure 9. Costs due to non-spinning reserve provision at 'A1'scenario with varying average energy prices and water inflow

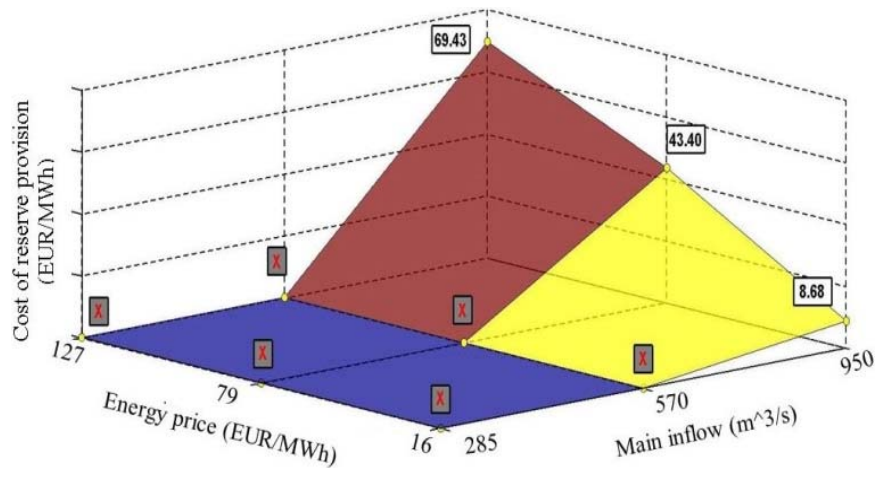

Figure 10. Costs due to spinning reserve provision at 'A1'scenario with varying average energy prices and water inflow 


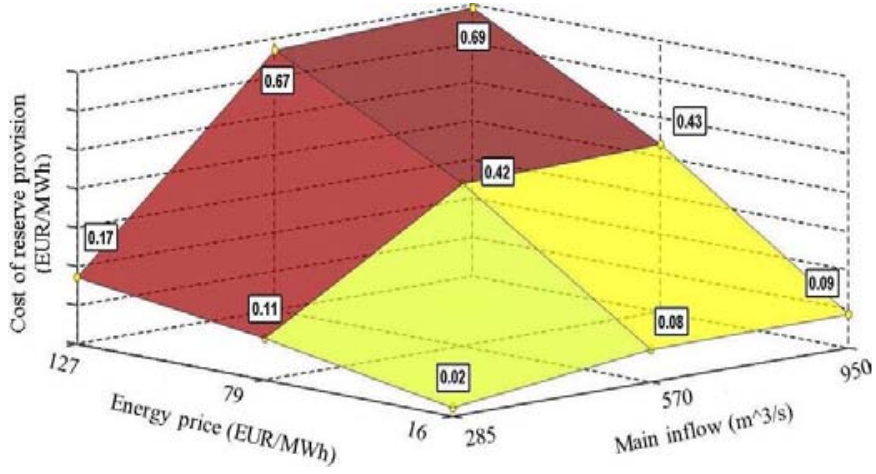

Figure 11. Costs due to non-spinning reserve provision at 'C'scenario with varying average energy prices and water inflow

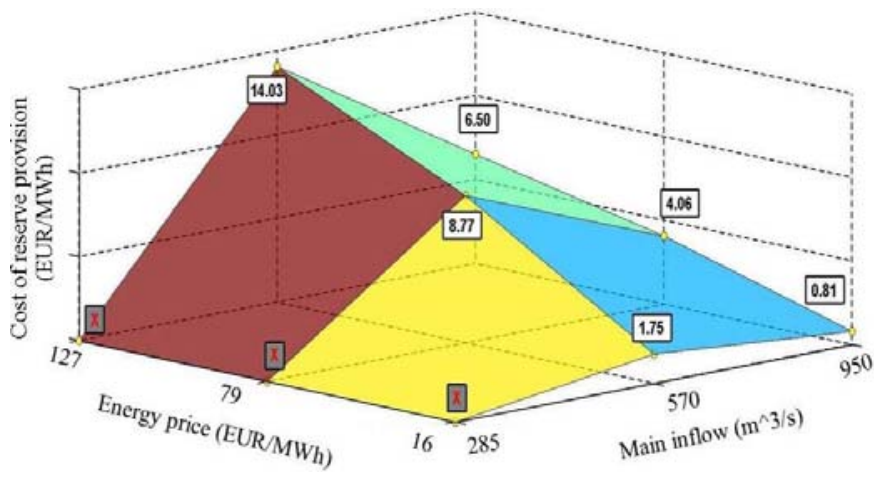

Figure 12. Costs due to spinning reserve provision at 'C'scenario with varying average energy prices and water inflow

Scenarios ' $D$ ' and ' $E$ ' which have the smallest amounts of reserved energy (1 $800 \mathrm{MWh}$ and $900 \mathrm{MWh}$ ) also provide interesting results. Unlike in most of the previous scenarios which saw higher costs with higher inflows, these are similar to ' $\mathrm{C}$ ' scenario for the SR mode in that smaller inflow values result in higher reserve provision costs. However, unlike in ' $\mathrm{C}$ ', in these two cases, the desired reserves can be provided also with low inflow values.

\section{CONCLUSIONS}

Our previously developed cascaded HPP scheduling model has been updated with functionality which simultaneously with solving the scheduling optimization problem also estimates the costs of operating reserve provision. The enhanced model has been tested using meteorological and market data from Latvia and technical characteristics of the cascaded HPPs on the Daugava River.

If a power producer cannot fully participate in an energy wholesale market due to constraints imposed by a necessity to provide reserves, the power production schedule is inevitably suboptimal. By comparing the potential day-ahead profit in an unconstrained operational mode to profit attainable if some capacity is reserved one can estimate the minimum remuneration necessary to make reserve provision an attractive business opportunity for the owners of a power production company.

In the case study, we found that water inflow volatility has a very notable effect on the opportunity costs of reserve provision. For relatively high amount of reserved energy higher inflow resulted in larger reserve provision costs than in cases with smaller inflow. Furthermore, sometimes the desired reserve energy cannot be offered due to insufficient inflow. However, if the amount of reserve energy is relatively smaller, this characteristic flips and reserves become more costly in the cases with small inflow.

This effect can be explained in the twofold way reserve provision hinders effective participation in day-ahead market for an HPP. The more inflow there is, the higher would be the profits if the HPP could schedule its production in an unconstrained manner during the hours with the highest electricity market price. Thus, the larger non-spinning reserves are required, the lesser is the HPPs ability to exploit its notable water resources lucratively. On the other hand, when the inflow is small, spinning reserves which act as a must-run capacity cause more hindrance than during large inflows, since in the latter case a poundage hydroelectric plant would likely run at the hours with the highest prices anyway, but if the water resources are very limited, more freedom in their use is needed to achieve close to optimum profitability.

\section{REFERENCES}

[1] Climate and Energy Package, European Commission. 2020. [Online]. Available: http://ec.europa.eu/clima/policies/strategies/2020/index_en.html

[2] Nord Pool electrical energy price statistics. [Online]. Available: http://www.nordpoolspot.com/Market-data1/Elspot/AreaPrices/LV/Hourly/?view=table. [Accessed: 03-Apr-2017].

[3] G. Verbic, F. Gubina, "Cost-based models for the power-reserve pricing of frequency control," IEEE Trans. Power Systems, vol. 19, No. 4, pp. 1853-1858, Nov. 2004.

[4] J. Li, Z. Li, "Multi-market bidding strategy considering probabilistic real time ancillary service deployment", in IEEE Proc. 2016 IEEE Electrical Power and Energy Conference (EPEC), pp. 1-8.

[5] J. Wang, M. Shahidehpour, Z. Li, "Contingency-constrained reserve requirements in joint energy and ancillary services auction", IEEE Trans. Power Systems, vol. 24, No. 3, pp. 1457-1468, Aug. 2009

[6] V. Siriariyaporn, M. Robinson, "Co-optimization of energy and operating reserve in real-time electricity markets", in Proc. 2008 The 3rd International conference on deregulation and restructuring and power Technologies., pp. 577-582.

[7] A. Virag, A. Jokic, R.M. Hermans, P.P.J. van den Bosch, "Combined bidding at power and ancillary service markets", in Proc. 2011 IEEE 8th International Conference on the European Energy Market., pp. 568-574.

[8] A. Sauhats, R. Varfolomejeva, R. Petrichenko, and J. Kucajevs, "A stochastic approach to hydroelectric power generation planning in an electricity market, " in Proc. 2015 IEEE 15th International Conference on Environment and Electrical Engineering., pp. 883-888.

[9] A. Sauhats, R. Petrichenko, K. Baltputnis, Z. Broka, R. Varfolomejeva, "A Multi-Objective Stochastic Approach to Hydroelectric Power Generation Scheduling," in Proc. 2016 IEEE Power Systems Computation Conference., pp. 56.-62.

[10] Cabinet of Ministers Regulation Nr. 736. Regulations on the use of water resources permits. [Online]. Available: http://likumi.lv/doc.php?id=82574

[11] Latvian Water Management Law. [Online]. Available: $\mathrm{http}: / /$ likumi.lv/doc.php?id=66885

[12] Use of water resources permit Nr. MA10DU0019 Latvenergo JSC Plavinu HES, The Ministry of Environmental Protection of the Republic of Latvia

[13] Larvenergo AS, Plavinas Hydroelectric power plant. [Online]. Avaliable: https://www.latvenergo.lv/hpptour/hpp_plavinas.html\# 